N. Mba, MBBS (Lagos), MSc, O.O. Famuyiwa, MPhil (Edin), FRCPsych, FWACP and O.F. Aina, MBChB, FWACP, Department of Psychiatry, College of Medicine, University of Lagos, PMB 12003, Lagos, Nigeria

\title{
PSYCHIATRIC MORBIDITY IN TWO URBAN COMMUNITIES IN NIGERIA
}

\author{
N. MBA, O.O. FAMUYIWA and O.F. AINA
}

\begin{abstract}
Background: There is a welter of evidence for an inverse relationship between socio-economic status (SES) and mental health. The relationship is grossly under researched in the developing countries.

Objective: To ascertain rates of gross psychiatric morbidity and some demographic correlations in two communities with different socio-economic standards.

Design: A cross-sectional community based study.

Subjects: Random samples of two socio-economically dissimilar communities $(\mathrm{N} 1=189, \mathrm{~N} 2=148)$ were assessed for psychiatric morbidity.

Results: Rates of psychiatric morbidity obtained for the lower status community (Ajegunle) and the higher status community (Victoria Island/Ikoyi) on the GHQ-12 were 26.5 and 14.2 respectively and the corresponding figures on the SRQ (non-psychosis) were 41.8 and 18.2 and on the SRQ (psychosis) 61.5 and 31.7. A large number of positive socio-demographic correlations between cases and non-cases were obtained on SRQ and GHQ-12 in both communities. Family history of psychiatric illness significantly differentiates cases from non-cases on all measures of morbidity. Conclusion: The socio-economic inequality demonstrated should be minimised by evolving a social welfare policy in Nigeria and other developing countries that is responsive to the survival needs of the populace and ensures equitable distribution of resources across socio-economic strata. There is dire need for further research into the complex bearings of the link between social status and psychological wellness in the developing world.
\end{abstract}

\section{INTRODUCTION}

The link between socio-economic status and health has been recognised for nearly two centuries (1) and there is ample evidence of a significantly higher prevalence among people of low socio-economic status of psychiatric disorder in general (2) persistent depression (3) and neurotic disorder (4).

A social-class gradient thus found in these studies and several others is gross regardless of the macro-indicators of socio-economic class : income, education or area of residence.
The relationship between social class and bipolar affective disorder was less researched and the scanty literature contains conflicting findings. For example, an excess of bipolar disorder had been found in the upper social classes (5) - a finding putatively attributed among other factors to creativity of the membership of the upper class but other studies (6) did not conclusively demonstrate such a relationship.

Other relevant area of enquiry was the clinical dimension model which contends that social class distribution of affective disorder might relate to 
severity of illness rather than syndromal content as proposed in two surveys which found that the rate of depressive disorder was twice or thrice as high among the low-class workers as among the upperclass workers (7) but later and better controlled large scale studies did not demonstrate a significant social class disparity.

In the developing world, which has a high rate of poverty, urban decay and poor social welfare policy, there has been paucity of systematic studies on the subject. However the few documented works delved on rural-urban differences, which along with other factors have a common ground in poverty. For instance in Sao Paulo, Brazil, a higher rate of psychiatric morbidity was found among poor families living in shanty towns compared with the dwellers of adjacent high-income modern areas (8) just as in the same country, Santana demonstrated a correlation between the prevalence of psychiatric morbidity (predominantly of neurotic and psychosomatic disorders) and income in the district of Salvador, while Almeido-Filho (9) highlighted employment status as a more important factor in mental health than area of domicile. Curiously, the findings on the developing countries alluded to above were not replicated in several studies from India which revealed that the prevalence of schizophrenia was higher in the upper castes than among the lower castes (10). Perhaps, increased mortality and better recovery rate among the lower caste could be important factors to account for the unusual finding. Alternatively, the social class bias could be different for different psychiatric syndromes.

The subject remains topical and its extension to response to pharmacotherapy during the late 1970s which proved inconclusive had excited fresh research fervors. For instance in a recent controlled study (11) it was demonstrated that residents of a low-income area are less likely to respond favourably to a combination of antidepressant medication and psychosocial intervention.

There is no systematic study in sub-Saharan Africa to date that specifically addressed the relationship between social class and psychiatric morbidity and yet unravelling such a relationship has a two-fold significance. First, knowledge of differential prevalent rates across social classes will prove useful indeed in defining priority in community mental health service planning and in marshalling argument in political advocacy for improved social welfare policy in general. Secondly, insights into the contribution of environmental adversities to the pool of community psychiatric morbidity could be gained.

We set out to compare psychiatric morbidity between two communities; Ajegunle, AG (lower soclo-economic class) and Victoria Island/Ikoyi, VII (higher socio-economic class) within metropolitan Lagos (population 15.0 million) Nigeria, that differs grossly on major socio-economic variables (Table 1). In addition to the superior socio-economic features tabulated, dwellers of VII enjoyed several recreational facilities such as swimming pools, tennis courts and could afford private cars such that they depended very minimally on the unhealthy public transportation system of most parts of the metropolis.

\section{MATERIALS AND METHODS}

Sampling: A simple systematic sample of subjects resident in each of the communities was taken with each made up of adult occupants (18 years and above) of every fourth house of every fourth street, the houses and streets being serially numbered as enumerated in the National Census Board register. The choice of a restricted geographic area of investigation was necessitated by accuracy of defining boundaries and the need to reduce administrative cost. Consent of the two governing Local Government authorities was obtained.

Excluding unwilling subjects and those questionnaires with inadequate responses, a total of 337 subjects (189, AG and 148 VII) constituted the study sample. We believe that this sample size was adequate for a comparison purpose in that we were primarily concerned with measures of global psychiatric morbidity rather than rates of specific syndromes. The key demographic characteristics of the two communities are as displayed in Table 1.

Case finding: We employed two simple screening instruments namely, the General Health Questionnaire (GHQ) and the Self-Reporting Questionnaire (SRQ). The GHQ-12 is a simple instrument which is a short version of the 60-item GHQ which had been satisfactorily tested in at least 50 validation studies and has a wide international coverage in 40 languages in its utility and is particularly useful in estimating prevalence and outcome of psychiatric disorder in primary care population (12). Its value 
in the study of general population is based mainly on its inherent quality to define caseness, that is, differentiation of those subjects with self-perceived experiences of psychiatric disorder and those without such experiences. The GHQ has been found to be reliable and valid on a local population and a minimum score of five identifies a subject that would in all probability be regarded as disturbed by a psychiatrist. The self-reporting questionnaire is a 20-item widely used WHO instrument constructed to detect psychiatric disorder in primary care settings. It has been validated for a local population and a score of five grossly discriminates between cases and non-cases (13).

Data collection: The questionnaires were administered by two experienced field research assistants (briefed on patience and good approach) to consenting subjects, and were completed within an average of
25 minutes. Each research assistant was not informed of the intent to compare the two communities and one did not know the other's involvement in the study. The whole exercise spanned two weeks during which no major life events on a community scale occurred.

\section{RESULTS}

Morbidity rates: Employing two instruments of proven reliability and validity namely the GHQ-12 and the SRQ, rates of psychiatric morbidity were significantly different in the two urban communities that are distinguishable on key macro-indicators of socio-economic status (Table 2). Specifically the percentages of cases in the higher status community (VII) measured by the GHQ-12 were 14.2 and the corresponding figure for the lower status community (AG) was 26.5.

Table 1

Socio-economic disparity between the two communities

\begin{tabular}{|c|c|c|c|}
\hline \multicolumn{2}{|c|}{ Parameter } & \multirow{2}{*}{$\begin{array}{l}\text { Ajegunle } \\
\text { Less than US\$1.5/ day }\end{array}$} & \multirow{2}{*}{$\begin{array}{l}\text { Victoria Island/Ikoyi } \\
\text { US\$18/ day }\end{array}$} \\
\hline (i) & Average income & & \\
\hline (ii) & Population density & $111,768 / \mathrm{km}^{2}$ & $609 / \mathrm{km}^{2}$ \\
\hline (iii) & ${ }^{\circ}$ Occupation & $20.0 \%$ & $62.9 \%$ \\
\hline (iv) & ${ }^{+}$Education & $60.8 \%$ & $87.1 \%$ \\
\hline
\end{tabular}

(i) \& (ii) = Estimates based on National Planning and National Census Board Statistics, Abuja,

Nigeria (1999).

${ }^{\circ}=$ Percentage of subjects belonging to classes $1 \& 2$ (occupational class distribution scheme in appendix).

${ }^{+}=$Percentage of subjects who reported having completed secondary education.

Table $2^{*}$

Comparison of rates of 'probable' psychiatric morbidity in the two urban communities

\begin{tabular}{|c|c|c|c|c|c|c|c|c|}
\hline \multirow[t]{2}{*}{ Measure } & \multicolumn{2}{|c|}{$\begin{array}{l}\text { Ajegunle } \\
(\mathrm{n}=189)\end{array}$} & \multicolumn{2}{|c|}{$\begin{array}{l}\text { Victoria Island / } \\
\text { Ikoyi }(\mathrm{n}=148)\end{array}$} & \multicolumn{2}{|c|}{ Total $(\mathrm{n}=337)$} & \multirow[t]{2}{*}{$X^{2}$} & \multirow[t]{2}{*}{ P-value } \\
\hline & No. & $(\%)$ & No. & $(\%)$ & No. & $(\%)$ & & \\
\hline $\mathrm{GHQ} \geq 5$ & 50 & 26.4 & 21 & 14.2 & 71 & 21.1 & 6.79 & $\begin{array}{l}0.009 \\
\text { (Yated corrected) }\end{array}$ \\
\hline $\begin{array}{l}\mathrm{SRQ} \geq 5 \\
\text { (Non-Psychosis) }\end{array}$ & 79 & 41.8 & 27 & 18.2 & 106 & 31.4 & 20.28 & 0.001 \\
\hline SRQ $\geq 1$ (Psychosis) & 91 & 61.5 & 26 & 13.7 & 117 & 34.7 & 81.34 & 0.001 \\
\hline
\end{tabular}

* Table does not show data on non-cases (i.e. those scoring less than 5 on GHQ and less than 5 on SRQ

- (non-psychosis) and less than 1 on SRQ (Psychosis) 


\section{Table 3}

Socio-demographic profile of GHQ-positives

\begin{tabular}{|c|c|c|c|c|c|}
\hline Factor & $\begin{array}{l}\text { Cases } \\
(\mathrm{n}=71)\end{array}$ & $\begin{array}{l}\text { Non-cases } \\
(\mathrm{n}=266)\end{array}$ & $X^{2}$ & $\mathrm{df}$ & ${ }^{*} \mathrm{P}$-value \\
\hline \multicolumn{6}{|l|}{ Age (years) } \\
\hline $17-26$ & 30 & 90 & & & \\
\hline $27-36$ & 30 & 84 & 6.73 & 2 & $0.034^{*}$ \\
\hline$\geq 37$ & 11 & 86 & & & \\
\hline \multicolumn{6}{|l|}{ Sex } \\
\hline Males & 36 & 144 & 0.53 & 2 & 0.553 \\
\hline Females & 36 & 122 & & & (Yates Corrected) \\
\hline \multicolumn{6}{|l|}{ Occupation } \\
\hline 1 & 7 & 40 & & & \\
\hline 2 & 17 & 68 & 22.82 & 3 & $0.001^{*}$ \\
\hline 3 & 19 & 78 & & & \\
\hline 4 & 16 & 11 & & & \\
\hline \multicolumn{6}{|l|}{ Civil status } \\
\hline Single & 36 & 130 & & & \\
\hline Married & 26 & 123 & 6.42 & 2 & $0.040^{*}$ \\
\hline Others & 9 & 13 & & & \\
\hline \multicolumn{6}{|l|}{ Religion } \\
\hline Christianity & 49 & 223 & & & \\
\hline Islam & 15 & 36 & 10.71 & 2 & $0.004^{*}$ \\
\hline Others & 7 & 7 & & & \\
\hline \multicolumn{6}{|l|}{ Education } \\
\hline None & 20 & 23 & & & \\
\hline Primary & 10 & 40 & 19.54 & 3 & $0.001^{*}$ \\
\hline Secondary & 17 & 90 & & & \\
\hline Tertiary & 24 & 113 & & & \\
\hline \multicolumn{6}{|l|}{ Number of children } \\
\hline None & 98 & 80 & & & \\
\hline 1 or 2 & 40 & 27 & 2.68 & 2 & 0.261 \\
\hline$\geq 3$ & 51 & 41 & & & \\
\hline \multicolumn{6}{|c|}{ Number of cohabitants } \\
\hline None & 14 & 39 & & & \\
\hline $1-3$ & & 30 & 69.27 & 2 & $0.001^{*}$ \\
\hline 4 and more & & 157 & & & \\
\hline Family history & & & & & $0.001^{*}$ \\
\hline Positive & 22 & 28 & 18.33 & 2 & (Yates Corrected) \\
\hline Negative & 46 & 236 & & & \\
\hline
\end{tabular}

${ }^{*} \mathrm{P}$ is significant

On the SRQ (non-psychosis component) the percentage of cases in the higher status community (VII) and low status community (AG) were 18.2 and 41.8 respectively. A very high percentage of cases (61.5) on SRQ (psychosis component) were obtained for the low status community (AG) while on the same subscale for VII the corresponding figure was 13.7. 
Socio-demographic correlations:

(i) All Subjects: For the GHQ scores, only sex and number of children, did not significantly differentiate between cases and non-cases when all subjects are considered together (Table 3). And for the SRQ Scores (non-psychosis) civil status, religion and number of cohabitants did not significantly differentiate between cases and non-cases for all subjects (Table 4). For the SRQ scores (psychosis) age, occupation, education and number of cohabitants differentiated between cases from non-cases (Table 5).

Table 4

Socio-economic profile of SRQ (non-psychosis) positives

\begin{tabular}{|c|c|c|c|c|c|}
\hline Factor & $\begin{array}{c}\text { Cases } \\
(\mathrm{n}=106)\end{array}$ & $\begin{array}{c}\text { Non-cases } \\
(\mathrm{n}=231)\end{array}$ & $X^{2}$ & df & ${ }^{*} \mathrm{P}$-value \\
\hline \multicolumn{6}{|l|}{ Age (years) } \\
\hline $17-26$ & 48 & 78 & 9.31 & 2 & $0.009^{*}$ \\
\hline $27-36$ & 39 & 75 & & & \\
\hline$\geq 37$ & 19 & 78 & & & \\
\hline \multicolumn{6}{|l|}{ Sex } \\
\hline Males & 52 & 127 & 38.11 & 3 & $0.001^{*}$ \\
\hline Females & 54 & 104 & & & \\
\hline \multicolumn{6}{|l|}{ Occupation } \\
\hline 1 & 10 & 37 & & & \\
\hline 2 & 25 & 60 & 14.91 & 3 & $0.002^{*}$ \\
\hline 3 & 29 & 68 & & & \\
\hline 4 & 17 & 10 & & & \\
\hline \multicolumn{6}{|l|}{ Civil status } \\
\hline Single & 60 & 106 & 9.59 & 2 & 0.247 \\
\hline Married & 35 & 114 & & & \\
\hline Others & 11 & 11 & & & \\
\hline \multicolumn{6}{|l|}{ Religion } \\
\hline Christianity & 80 & 192 & 2.80 & 2 & 0.247 \\
\hline Islam & 20 & 31 & & & \\
\hline Others & 6 & 8 & & & \\
\hline \multicolumn{6}{|l|}{ Education } \\
\hline None & 24 & 19 & & & \\
\hline Primary & 12 & 38 & 14.83 & 3 & $0.002^{*}$ \\
\hline Secondary & 34 & 74 & & & \\
\hline Tertiary & 36 & 101 & & & \\
\hline \multicolumn{6}{|l|}{ Number of children } \\
\hline None & 58 & 130 & 11.02 & 2 & $0.004^{*}$ \\
\hline 1 or 2 & 23 & 44 & & & \\
\hline$\geq 3$ & 25 & 57 & & & \\
\hline \multicolumn{6}{|c|}{ Number of cohabitants } \\
\hline None & 20 & 33 & & & \\
\hline $1-3$ & 28 & 64 & 1.15 & 2 & 0.561 \\
\hline$\geq 4$ & 58 & 134 & & & \\
\hline \multicolumn{6}{|l|}{ Family history } \\
\hline Positive & 29 & 21 & 18.04 & 18.04 & $0.001^{*}$ \\
\hline Negative & 75 & 207 & & & \\
\hline
\end{tabular}

${ }^{*} \mathrm{P}$ is significant 


\section{Table 5}

Socio-economic profile of $S R Q$ (psychosis) positives

\begin{tabular}{|c|c|c|c|c|c|}
\hline Factor & $\begin{array}{c}\text { Cases } \\
(\mathrm{n}=106)\end{array}$ & $\begin{array}{c}\text { Non-cases } \\
(\mathrm{n}=231)\end{array}$ & $X^{2}$ & $\mathrm{df}$ & ${ }^{*} \mathrm{P}$-value \\
\hline \multicolumn{6}{|l|}{ Age (years) } \\
\hline $17-26$ & 93 & 33 & & & \\
\hline $27-36$ & 71 & 43 & 6.94 & 2 & $0.031^{*}$ \\
\hline$\geq 37$ & 56 & 41 & & & \\
\hline \multicolumn{6}{|l|}{ Sex } \\
\hline Males & 115 & 64 & 0.18 & 3 & 0.756 \\
\hline Females & 105 & 53 & & & \\
\hline \multicolumn{6}{|l|}{ Occupation } \\
\hline 1 & 18 & 29 & & & \\
\hline 2 & 50 & 35 & 24.02 & 3 & $0.001^{*}$ \\
\hline 3 & 72 & 25 & & & \\
\hline 4 & 23 & 4 & & & \\
\hline \multicolumn{6}{|l|}{ Civil status } \\
\hline Single & 117 & 49 & 4.61 & 2 & 0.099 \\
\hline Married & 88 & 61 & & & \\
\hline Others & 14 & 8 & & & \\
\hline \multicolumn{6}{|l|}{ Religion } \\
\hline Christianity & 172 & 100 & 3.33 & 2 & 0.189 \\
\hline Islam & 39 & 12 & & & \\
\hline Others & 10 & 4 & & & \\
\hline \multicolumn{6}{|l|}{ Education } \\
\hline None & 33 & 10 & & & \\
\hline Primary & 33 & 17 & 30.73 & 3 & $0.001^{*}$ \\
\hline Secondary & 84 & 23 & & & \\
\hline Tertiary & 71 & 66 & & & \\
\hline \multicolumn{6}{|l|}{ Number of children } \\
\hline None & 119 & 59 & & & \\
\hline 1 or 2 & 42 & 25 & 0.45 & 2 & 0.799 \\
\hline$\geq 3$ & 59 & 33 & & & \\
\hline \multicolumn{6}{|c|}{ Number of cohabitants } \\
\hline None & 33 & 20 & & & \\
\hline $1-3$ & 54 & 38 & 14.45 & 2 & $0.002^{*}$ \\
\hline$\geq 4$ & 133 & 59 & & & \\
\hline \multicolumn{6}{|l|}{ Family history } \\
\hline Positive & 36 & 14 & 0.91 & 2 & 0.339 \\
\hline Negative & 180 & 102 & & & \\
\hline
\end{tabular}

${ }^{*} \mathrm{P}$ is significant

(ii) Differences between the two communities: Considering correlations on the GHQ scores for each of the two communities, the information that emerged is the significant correlation in both communities on the family history of psychiatric illness.
AG $\left(\mathrm{X}^{2}=10.55, \mathrm{df}=1, \mathrm{P}<0.001\right)$ and VII; $\left(X^{2}=7.00 \mathrm{df}=1 \mathrm{P}<0.008\right)$. The other three significant correlates for Ajegunle (low income community) are age, $\left(\mathrm{X}^{2} 10.45, \mathrm{df}\right.$ $2, \mathrm{P}<0.005)$ occupation $\left(\mathrm{X}^{2}=23.41, \mathrm{df}=3\right.$, $\mathrm{P}=0.001)$. 
Table 6

Demographic correlations

\begin{tabular}{lcccccc}
\hline GHQ-12 & \multicolumn{3}{c}{$\begin{array}{c}\text { Ajegunle } \\
(\mathrm{n}=189)\end{array}$} & \multicolumn{3}{c}{$\begin{array}{c}\text { Victoria Island / Ikoyi } \\
\text { (n=148) }\end{array}$} \\
& $\mathrm{X}^{2}$ & $\mathrm{df}$ & $\mathrm{P}^{+}$ & $\mathrm{X}^{2}$ & $\mathrm{df}$ & P-value \\
\hline Age & 10.45 & 2 & $0.005^{*}$ & 0.10 & 2 & 0.948 \\
Sex & 0.29 & 1 & 0.592 & 0.10 & 1 & 0.940 \\
Occupation & 16.92 & 3 & $0.001^{*}$ & 6.31 & 3 & 0.097 \\
Civil status & 2.79 & 2 & 0.247 & 3.30 & 2 & 0.192 \\
Religion & 3.24 & 2 & 0.198 & 1.89 & 2 & 0.388 \\
Education & 23.41 & 3 & $0.001^{*}$ & 5.77 & 3 & 0.123 \\
Number of children & 2.34 & 2 & 0.311 & 1.08 & 2 & 0.583 \\
Number of cohabitants & 1.91 & 2 & 0.385 & 2.74 & 2 & 0.254 \\
Family history & 10.55 & 1 & $0.001^{*}$ & 7.00 & 1 & 0.008 \\
SRQ & & & & & & \\
Age & & & & & & \\
Sex & 5.58 & 2 & 0.061 & 1.54 & 2 & 0.464 \\
Occupation & 0.55 & 1 & 0.458 & 0.50 & 1 & 0.481 \\
Civil status & 8.01 & 3 & $0.045^{*}$ & 6.14 & 3 & 0.105 \\
Religion & 5.57 & 2 & 0.061 & 4.83 & 2 & $0.089^{*}$ \\
Education & 5.95 & 2 & 0.139 & 7.91 & 2 & $0.019^{*}$ \\
Number of children & 11.91 & 3 & 0.007 & 2.94 & 3 & 0.401 \\
Number of cohabitants & 1.05 & 2 & 0.591 & 1.28 & 2 & 0.527 \\
Family history & 0.68 & 2 & 0.710 & 0.76 & 2 & 0.683 \\
\hline
\end{tabular}

Similarly on SRQ-20 (non-psychosis) Table 6, the significant correlations were obtained on family history for both communities. Furthermore for Victoria Island, specifically, civil status and religion were significant correlates while for Ajegunle, occupation, education, were also significant. The SRQ-(psychosis) (not in Table 5) significantly differentiates cases from non-cases in Ajegunle only, on age; $\mathrm{X}^{2}=13.02 ; \mathrm{df}=2 ; \mathrm{P}<0.001$. No significant correlates were elicited for VII. Summing up therefore;

(a) There were higher morbidity scores on the SRQ on both (non-psychosis) and (psychosis) components of the SRQ than on the GHQ-12.

(b) Also there were more significant correlates on the SRQ than on the GHQ-12.

(c) Family history significantly differentiates between cases and non-cases on all the measures of morbidity employed supporting the probability of hereditary anlage in psychopathology.

\section{DISCUSSION}

The relationship between socio-economic status and mental health is complex in that it forms the matrix of the inter-phase of social, cultural and political processes in any community. It follows therefore that any researcher would be confronted with the onerous task of sifting out several variables and determining their weightings in the genesis of mental pathology. The problem is particularly compounded by the often unsuccessful exercise of unraveling whether the conventional macroindicators of socio-economic status are causes or effects of mental ill-health.

Notwithstanding these reservations, we believe that the link probable aetiologic, between socioeconomic structure and gross measure of psychiatric morbidity is corroborated in this study. And we adopt the customary approach to explaining the observed differences in psychiatric morbidity between the two economically disparate communities by considering 
the three well known mechanisms; namely the social drift hypothesis, breeder (social stress) hypothesis and the neuro-developmental theory.

First, the 'social drift' hypothesis which explains the low economic status of urban dwellers in terms of social and cognitive degeneracy and consequent decline of personal capabilities essential for personal success is certainly not elicitable in the context of our modest screening measurements and the lack of baseline data on pre-illness mental status. Furthermore, we did not have reliable information on the social class distribution of parents of the respondents hence degeneracy could not be elicited.

The breeder (social stress) hypothesis implicates adverse social and economic conditions in the genesis of psychiatric morbidity, and is supported by our findings in that the relevant data fit in with the well-known differences in the socio-economic parameters between the two communities.

Ajegunle (low status) epitomises the under privileged urban decaying community with a high rate of poverty, overcrowding, low literacy and over representation at the lower occupational classes three and four.

The other dimension is that the finding of the observed differences in psychiatric morbidity might reflect lesser utilisation of psychiatric services is not supported in this study that was a community survey rather than institution-based enquiry.

Related to the social stress theory is the probable contribution of neuro developmental pathologies to the observed differences in psychiatric morbidity between the two communities and the best studied of these pathologies are the obstetric complications (OCs) such as pre-eclampsia, antenatal haemorrhages, which in controlled studies have been implicated in the pathogenesis of mental disorder (14). Also, obstetric difficulties contribute to the aetiology of mild learning disability, which have been shown to be precursors of behavioural deviances by 21 years of age (15). Furthermore, it is common knowledge that under-nutrition, poor education, several types of infectious - mostly parasitic are prevalent in the socio-economically under-privileged communities majority of which are in the developing countries.

Though, we did not specifically examine association of obstetric complications, infections, and poor education and under nutrition with socio- economic status, however we believe that these factors might account for the disparity in psychiatric morbidity between the two communities studied.

It is interesting to note that a school of thought not unrelated to the 'breeder' hypothesis indicts attitudinal variables such as beliefs, customs, perception of problems and personal coping resources as constituting the origin of psychiatric morbidity among the low - income groups and to ascertain the relevant links would entail careful and extensive correlations of validated measures of attitude-coping complexes but such studies are to date yet to be systematically undertaken, however it is expedient to take cognisance of coping styles and adaptive capacity as a primary preventative strategy in providing services targeted to high-risk low-income populations.

In general, it would appear that different hypotheses apply predominantly to different psychopathology. For example the 'drift' hypothesis is considered valid for the risk of schizophrenia and the breeder hypothesis supports the genesis of moderate depression among the low class in urban areas.

The other issue of note is the rural-urban dichotomy which was felt to be an important factor in differential health status. Half of urban population in the developing countries live at the level of extreme poverty and equally disturbing is the recent enormous increases in urban dwellers in Africa, Asia and Latin America without accompanying increase in prosperity, but it has been realised that neither rural nor urban domicile is a reliable predictor of mental disorder and that poverty and unemployment status are the prime factors. For example though low-income is more common in rural areas, poor city dwellers (such as Ajegunle residents in this study) suffer more from some complications of poverty than rural dwellers.

However it should be stated for the sake of planning of services, that prosperity does not necessarily translate to satisfactory mental health in that peculiar local social forces are equally important as demonstrated by epidemiological studies on Western Europe and United States of America which revealed significant increase in the rates of psychosocial disorders interalia conduct disorder, substance misuse, depression, suicide and eating disorders among youths during the period (1950-1973) of social and economic upsurge (37). 
Another dimension receiving increasing attention in recent period is the observation that economic prosperity does not get to different communities equally and significant inequalities have been noted internationally in the developing countries as in the case of Brazil, where the top twenty per cent earned 26 times more than what the bottom twenty per cent earn (16). Though there are no accurate figures for Nigeria, empirical observations indicate rich-poor differences comparable to what obtains in several other developing countries. Income inequality, is a poorly understood demographic variable, but available evidence indicate a linear relationship with mortality self-rated health $(17,18)$ but with probable mediation by psychosocial stresses.

The finding of greater number of significant demographic correlates - three on SR4-20 responses compared with only one GHQ responses for Victoria Island/Ikoyi (Table 6) seems to indicate greater accuracy of the SRQ in case detection a finding which supports the axiom that the type of instrument could be a determinant of the level of morbidity.

Correlates on the SRQ - (psychosis) are difficult to interpret partly because the four questions of this component of SRQ (for example): Do you feel that somebody has been trying to harm you in some ways? Descriptively have weak discriminatory power on health - illness continuum in that they approximate in content with patterns of culturally acceptable thinking resulting in high rate of false positives!

\section{CONCLUSION}

It is evident that the measures and policies that would potentially minimise the urban socio-economic inequalities as elicited in this study should be directed at the political system and social policy.

First, the economy of Nigeria, as of that of several other sub-Saharan countries are to a large extent dictated by the international economic equation dominated by the over- riding economies of the industrialised nations. For instance, global economic recession in the last two decades had reduced growth rate of industrialised nations with resultant pegging of their aid to the low-income developing countries, Nigeria inclusive.

The other problem is that the cheap industrial labour of the developing countries is becoming less relevant to the superior and stable economies of the industrialised countries and furthermore the fact that the weak export -orientation of the developing countries had contributed to economic stagnation; the resultant effect being over-dependence on World market which could not very often be relied on considering the exigency of economic survival and the need for growth of the developed countries. More lamentable is the factor of political instability based predominantly or inter-communal strife, selfcentred political ambition and a basic inability to fashion out an appropriate political system adapted to the needs of individual nations.

To buttress this point, successful economic reforms, buoyant export economy, political stability, expanding educational wherewithal have led to phenomenal upsurge in the economies of some South East Asian countries - (e.g. Taiwan) including coastal China, leading to increased quality and availability of education and improved mental health care system (19). The same experience had been documented for Mexico and Argentina (20).

As a recipe for desired changes we would like to emphasis that the onus for a responsive social welfare policy in the developing countries in general would rest on the citizens who should mobilise crusade through constructive advocacy for reduction in poverty as borne out by the American experience expressed in Michael Harrington's. "The Other America"

Finally, it should be illuminating to note whether levels of mental health care could be influenced by different socio-economic statuses. And this dimension and related ones would be our future targets of enquiry.

\section{ACKNOWLEDGEMENTS}

We are immensely grateful to; Mr. Akin Dawodu of the National Census Board, Lagos for access to key demographic data on the Local Government areas studied, Dr Brian Lockner of the Social Science Research unit. Ikoyi, Lagos for his critique of the paper and Ms Bola Peters for secretarial services.

\section{REFERENCES}

1. Adler, N.E., Boyce, T., Chesney, M.A., Cohen, S., et al . Socio-economic status ad health: The challenge of the gradient. Amer. Psychol. 1994; 49: 15-24. 
2. Kessler, R.C., McGonagle, K.A., Zhao, S., et al. Lifetime and 12-month prevalence of DSM-III-R psychiatric disorders in the United States. Arch. Gen. Psychiat. 1994; 51: 8-19.

3. Gilman, S.E. Review: There is marked socio-economic inequality in persisted depression. Evidence-basedmental health. 2003; 6: 75.

4. Lewis, G., Bebbington, P., Brugha, T., et al. Socioeconomic status, standard of living and neurotic disorder. Lancet. 1998; 352: 605-609.

5. Bagley, C. Occupational class and symptoms of depression. Social Sci. Med. 1973; 7: 327-339.

6. Bebbington, P.E. The social epidemiology of clinical depression. In: Handbook of studies in social psychiatry (ed. A.S. Henderson and G. Burrout), Elsevires Amsterdam, 1988; 87-102.

7. Harris, T. Recent development in understanding the psychosocial aspects of depression. Brit. Med. Bull. 2001; 57: 17-32.

8. Mari, J. Psychiatric morbidity in three primary medical care clinics in the city of Sao Paulo. Social Psychiat. 1987; 22: $129-138$.

9. Almeido-Filho, N. The psychosocial costs of development, labour, migration and stress in Bahia, Brazil. Latin Amer. Res. Rev. 1982; 17: 91-118.

10. Dube, K.C. and Kumar, N. Epidemiological study of schizophrenia. J. Biosoc. Sci. 1972; 4: 187-195.

11. Cohen, A., Houck, P.R., Szanto, K., et al. Social inequalities in response to antidepressant treatment in older adults. Arch. Gen. Psychiat. 2006; 63: 50-56.

12. Weich, S., Phelam, M. and Mann, A. Measurement in psychiatry, in the essentials of postgraduate psychiatry (Ed Murray, R. Hill, P. and McGuffin, 3rd Edn). Cambridge, 1997; 65-85.

13. Abiodun, O. Sensitivity and validity of the selfreporting questionnaire in a primary health centre in a rural community in Nigeria. Psychopathologic Africaine. 1988; 221: 79-88.

14. Dalman, C., Allebeck, P., Cullberg, J., et al. Obstetric complications and the risk of schizophrenia. A longitudinal study of a national cohort. Arch. Gen. Psych. 1999; 56: 234-240.

15. Koller, H., Richardson, S.A., Katx, M.I., et al. Behavioural disturbance since childhood among a 5 year old birth cohort of all mentally retarded young adults in a city. Amer. J. Ment. Dis. 1983; 87: 386-395.

16. Brooke, J. A hard look at Brazil's surfeits: Food, hunger and inequality. The New York Times, June 6, 1993b.C 20.

17. Kaplan, G.A., Pamuk, E.R., Lynch, J.W., et al. Inequality in income and mortality in the United States. Analysis of mortality and potential pathways. Brit. Med. J. 1996; 312: 999-1003.

18. Wilkinson, R. Income distribution and life expectancy. Brit. Med. J. 1992; 304: 165-168.

19. Chang, L.Y. Mental health in Taiwan. Working paper. International Mental and Behavioural Health Project. Centre for the Study of Culture and Medicine Harvard Medical School, Boston, Massachusetts. 1993.

20. The Economist. Third World Finance: New ways to grow. 1993; 25: 5-44.

\section{APPENDIX}

Social class stratification

(i) executive managers, company directors, professionals (doctors, lawyers, engineers), university professors, traditional chiefs. Civil servants, nurses, professional teachers including University and Polytechnic Teachers, Secretaries.

(ii) (semi-skilled) tailors, bricklayers, carpenters (joiners)

(iii) Typists, sewing mistress, junior clerks).

(Iv) Unskilled - messengers, roadside hawkers, cleaners, nightguards.

Educational levels

0 No formal education

1 Primary school

2 Modern school

3 West African School Certificate (GCE "0" Level)

4 Post-Secondary Training/Education, e.g. nursing, printing, technician apprenticeship.

5 University/Polytechnic, Colleges 